\title{
Self-awareness in Dementia: a Taxonomy of Processes, Overview of Findings, and Integrative Framework
}

\author{
Daniel C. Mograbi ${ }^{1,2}$ (D) Jonathan Huntley ${ }^{3,4} \cdot$ Hugo Critchley $^{5,6}$
}

Accepted: 27 September 2021 / Published online: 24 November 2021

(c) The Author(s) 2021

\begin{abstract}
Purpose of Review Self-awareness, the capacity of becoming the object of one's own awareness, has been a frontier of knowledge, but only recently scientific approaches to the theme have advanced. Self-awareness has important clinical implications, and a finer understanding of this concept may improve the clinical management of people with dementia. The current article aims to explore self-awareness, from a neurobiological perspective, in dementia.

Recent Findings A taxonomy of self-awareness processes is presented, discussing how these can be structured across different levels of cognitive complexity. Findings on self-awareness in dementia are reviewed, indicating the relative preservation of capacities such as body ownership and agency, despite impairments in higher-level cognitive processes, such as autobiographical memory and emotional regulation.

Summary An integrative framework, based on predictive coding and compensatory abilities linked to the resilience of selfawareness in dementia, is discussed, highlighting possible avenues for future research into the topic.
\end{abstract}

Keywords Self-awareness $\cdot$ Interoception $\cdot$ Agency $\cdot$ Metacognition $\cdot$ Selfhood $\cdot$ Dementia

\section{Introduction}

Self-awareness is fundamental to psychology and the humanities, yet the topic remains at the frontier of scientific knowledge. Over centuries, distinct philosophical and religious traditions have grappled with the subject. In ancient

This article is part of the Topical Collection on Behavior

Daniel C. Mograbi

daniel.mograbi@kcl.ac.uk

1 Department of Psychology, Pontifical Catholic University of Rio de Janeiro, Rio de Janeiro, Brazil

2 Institute of Psychiatry, Psychology \& Neuroscience, King's College London, De Crespigny Park, PO Box 078, London SE5 8AF, UK

3 Division of Psychiatry, University College London, London, UK

4 Wellcome Centre for Human Neuroimaging, University College London, London, UK

5 Sackler Centre for Consciousness Science, University of Sussex, Brighton, UK

6 Psychiatry Department of Neuroscience, Brighton and Sussex Medical School, Brighton, UK
Greece, the maxim 'Know thyself' greeted visitors seeking foresight from the oracle at the Temple of Apollo at Delphi. Eastern traditions similarly emphasise the importance of insight and self-knowledge [1]. However, only recently has the importance of self-awareness been established as a central concept for scientific investigation, and to which scientific methods can be applied to explore and characterise this phenomenon [2].

Self-awareness can be defined as the capacity of becoming the object of one's own awareness [3]. This definition suggests a unitary, continuous model of self that can be observed and that itself acts as the observer. The self-model may be implicit but is revealed because it can enter conscious awareness, where it can be scrutinised. Nevertheless, a multiplicity of self-processes is encompassed within such a self-model [4, 5]. Self-awareness is thus dynamic, with inter-related yet heterogeneous aspects [6], each potentially dominating the self-model or awareness at a given time. For example, bodily self-awareness, including interoception (representation of one's internal body state) and proprioception (representation of one's body in space), can be phenomenologically distinguished from metacognitive thinking (awareness and evaluation of own thoughts), yet both are forms of self-awareness. Aspects of emotion, including the 
identification of affective feelings, may in part bridge these axes. Importantly, clinical conditions can lead to selective deficits of self-awareness, wherein specific abilities may be compromised, according to the profile of structural and functional brain alterations $[7 \bullet, 8]$.

Self-awareness has important implications, notably from a clinical perspective. Recognising and understanding alterations in self-awareness within patient groups may enhance clinical management of neurological and psychiatric conditions and inform novel therapeutic interventions. For example, rehabilitation of neurological patients with impaired self-awareness might best employ implicit (non-aware) adaptations $[9,10]$, whereas therapies for specific psychiatric 'disorders of self', in conditions including psychosis and bipolar disorder, can respond to targeted metacognitive training [11, 12]. Additionally, a comprehensive understanding of the neurobiological mechanisms of self-awareness and its distinct components will shed light on fundamental principles of brain functioning. This can have profound implications that may lead to a reappraisal of extant models of general cognitive and emotional processes. A finer understanding of self-awareness may also have broader social relevance; for example, quantifying the extent to which individuals, patient groups, species, and devices are self-aware may reshape operational definitions of legal responsibility and culpability.

Exploring self-awareness is particularly relevant in the context of dementia. Neurodegenerative processes impact long-established expressions of identity to the detriment of self-management and interaction with others, including family and carers. Here, the recognition of self-awareness as a heterogeneous process is composed of different elements that may be differentially and variably affected and may guide a finer evaluation of preserved and impaired abilities in dementia. This recognition is crucial to avoid care practices expressing 'malignant social psychology' [13], in which 'personhood' is neglectfully devalued alongside the progressive and cognitively debilitating effects of dementia. Individual and institutional caregiving practices may have depersonalizing, disempowering elements that stigmatize people with dementia (PwD), and further add to disability [13]. Here, a greater appreciation of how aspects of selfawareness are compromised or retained in dementia may enhance person-centred care practices that foster preserved abilities and retain personhood.

Considering the above, the current article appraises selfawareness from a neurobiological perspective and discusses how evidence obtained from the study of PwD increases our understanding of how self-awareness is organised in the human brain. For this purpose, distinct self-awareness processes will be considered, followed by a discussion on how self-awareness can be structured across different levels of cognitive complexity. Data obtained with PwD will be discussed in relation to self-awareness, leading to the suggestion of an integrative framework helping to establish future empirical research into this topic.

\section{A Taxonomy of Self-awareness}

As indicated above, self-awareness encompasses multiple dissociable processes (Table 1). This perspective is particularly relevant to understanding pathological neurocognitive alterations, for example in the case of dementia.

Theoretically, interoception, defined as the sense of physiological conditions of the body [14], is at the core of selfrepresentation and thus fundamental to self-awareness. Life depends on maintaining stability in the internal physiological state of the body through low-level homeostatic reflexes, and via adaptive and anticipatory (allostatic) responses that are coordinated across organ systems and motivate adaptive behaviours. The information flow from the body to the brain is integrated to provide an inescapable dynamic representation of the physical self that coordinates behavioural responses to meet current and future needs. While much is achieved implicitly, through autonomic reflexes, awareness first emerges as bodily sensations and affective states. Thus, interoception and its organism-level control provide

Table 1 A taxonomy of self-awareness

\begin{tabular}{|c|c|c|}
\hline Self-awareness processes & Definition & Neural correlates \\
\hline Interoception & $\begin{array}{l}\text { Sense of the physiological conditions of the entire } \\
\text { body }\end{array}$ & $\begin{array}{l}\text { Insula, subcortical, and brain stem regions linked to } \\
\text { homeostatic processes }\end{array}$ \\
\hline Proprioception and body ownership & $\begin{array}{l}\text { Mapping of the relative position of body parts, and } \\
\text { the feeling of owning a body, respectively }\end{array}$ & $\begin{array}{l}\text { Somatosensory cortex, thalamus, basal ganglia, } \\
\text { cerebellum, and motor areas }\end{array}$ \\
\hline Agency & Sense of generating our own actions & $\begin{array}{l}\text { Angular gyrus and other temporoparietal regions, } \\
\text { motor areas }\end{array}$ \\
\hline Metacognition & Monitoring, knowledge, and regulation of cognition & Anterior cingulate and frontal cortical regions \\
\hline Emotional regulation & Monitoring and regulation of emotion & Cortical-subcortical loops \\
\hline Autobiographical memory & $\begin{array}{l}\text { Records of self-information, including specific epi- } \\
\text { sodes and general knowledge about oneself }\end{array}$ & $\begin{array}{l}\text { Medial and lateral temporal regions and medial } \\
\text { prefrontal cortex }\end{array}$ \\
\hline
\end{tabular}


the basis to both a unitary biological self-object and the representation of this self as 'an agent' [15]. The latter is crystalized through interoceptive policies that adjust internal physiology in anticipatory and adaptive allostasis [15] and extend the biological self-model to encompass other correlated sources of sensory information $[15,16]$.

One influential model describes distinct psychological dimensions of interoception [17]. This model reflects different levels at which interoceptive information can be perceived and has proved useful in tightening nomenclature when studying contributions of interoception to cognitive and emotional processes. Within the brain, lower-level interoceptive inputs into the brainstem and subcortical regions support homeostatic reflexes, yet feed up into 'viscerosensory cortex' in the insula, where interoceptive information is integrated with other sensory and contextual information [18••]. Forward representation within anterior insular cortex supports feeling states through conscious access and appraisal of interoceptive sensations (putatively through comparison with expectations encoded as an efference copy of visceromotor drive from anterior cingulate cortex; [19]). In this way, generalised feelings concerning the overall state of internal bodily physiology can be evaluated against intended bodily arousal states appropriate for a selected behaviour.

Bodily self-awareness is bound by the representation of the physical extent of the body and the relative position of body parts in space, i.e. proprioception. Proprioception augments feelings of owning a body, and its self-location [20]. This outward focus of proprioception can also be differentiated from interoception (to which it is closely bound; $[18 \bullet \bullet])$. Within the brain, the somatosensory cortex, temporoparietal junctions, and a wider network of associated brain regions, including the thalamus, basal ganglia, cerebellum, and motor areas, contribute to the dynamic representation of proprioceptive information and awareness of one's physical presence within a spatial context (for a meta-analysis, see [21]). Aberrant functioning of this system is implicated in disorders of body ownership, in cases such as somatoparaphrenia [22].

In contrast to the largely implicit nature of interoceptive information, there is greater conscious access to, and awareness of, proprioceptive information and its direct relationship to the control of bodily state and position. This enhances the feeling of owning a body. The sense of generating our own actions, termed agency, is a key component of self-awareness [23, 24]. Agency is closely tied to action, and the feeling of agency encompasses self-efficacy through the cognitive feeling of voluntary control of one's actions. Unsurprisingly, models of agency typically suggest that an intention to move leads to a motor command, with a copy of that command (efference copy) being generated to predict the consequence of the command. This prediction is compared with feedback of the consequences of action, giving rise, when there is no mismatch, to the feeling of agency [23]. The parietal cortex, in particular temporoparietal regions, notably the angular gyrus, is particularly implicated in agency [23, 25]. As suggested above, interoceptive mechanisms may enhance feelings of agency through the viscerosensory consequences of 'central command' and efference copy from motor and cingulate cortices into the insular cortex $[19,26]$. The presence of Von Economo Neurons in the anterior insula and anterior cingulate cortices in certain 'higher' species, including great apes and especially humans, putatively links the evolution of specialised neural circuitry (cortical-brainstem systems potentially involved in interoceptive control) to greater self-awareness and insight [27, 28].

Metacognition, heuristically 'thinking about thinking', is fundamental to self-awareness, not least because it encompasses the appraisal of mental processes thoughts, emotional feelings, and perceptual representations. Here, the self is implicit; mental processes (cognitions) are objectified and 'owned' and appraised from a typically unitary self-perspective. Metacognitive measures of insight represent a strong index of awareness, particularly during psychological task performance: Both over- or under-estimating one's performance (or ability) translates to poor metacognitive awareness (insight), compared to knowing accurately if one performs well or badly. More generally, metacognition is a higher cognitive form of self-awareness, operationalised as the monitoring, knowledge, and regulation of cognitions [29]. These cognitions may involve previous information, experiences, emotions, and goals, including the formulation of cognitive strategies e.g. prospective problem solving [29]. Within the brain, metacognition is primarily linked to the medial and dorsolateral frontal cortical function [30]. For example, electroencephalography studies indicate that the dorsal anterior cingulate is a crucial structure in error monitoring processes [31] and associated psychophysiological reactions [32]. The ventromedial prefrontal cortex is engaged in self-referential processing and, relatedly, adjacent orbitofrontal cortices represent relative rewards, and the emotions engendered, including whether a reward was less than expected [33]. Similarly, the dorsolateral prefrontal cortex is recruited during self-monitoring of task perfor-

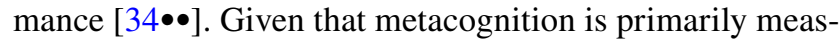
ured through self-report, the extent to which species other than humans can show metacognitive abilities is a source of debate. A few studies suggest metacognitive ability in primates and rodents (e.g. [35]), but methodological issues typically prevent firm conclusions [36].

Although generally distinguished from metacognition, emotional regulation engages similar processes, including thought and response monitoring and strategic regulation, but applied to emotion; i.e. valenced cognitions, affective 
feelings, and arousal. Emotional regulation strategies include changing the antecedents of an unwanted emotional experience, or regulating the emotional responses that form part of the experience [37]. Examples of 'mitigative' antecedentfocused emotional regulation include selective avoidance of evoking situations, attempts to modify such situations, attentional redeployment (e.g. distraction, mindfulness), and cognitive reappraisal [37]. Response-based regulation is generally less adaptive and includes strategies such as emotion suppression, substance abuse, and self-harm [38]. Antecedent-focused emotional regulation therefore entails a stronger model of self that can be protected into future counterfactual scenarios. The mechanisms linked to emotional regulation typically reflect interactions across cortical-subcortical neural substrates (e.g. amygdala and basal ganglia) [39]. For instance, prefrontal and anterior cingulate cortices are implicated in the active deployment of attention in emotional regulation (including distraction and reappraisal, and response suppression) [40].

Finally, in order to be available for future use, information about the self needs to be registered in time (as well as space). Self-based memories are referred to as autobiographical memory. Autobiographical memory can be divided into incident memory (encoding and recollection of specific episodes) and personal semantics (general knowledge about oneself; [41]). This conceptual distinction is supported by neuroimaging and lesion studies that distinguish brain networks for episodic and semantic components of autobiographical memories [41, 42]. Notably, the medial temporal cortex, including the hippocampus and surrounding cortical regions, is crucial for the encoding and recollection of incident memory [43]. Personal semantics share similar areas, but also engage regions linked to general semantic memory (e.g. lateral temporal lobe) and regions implicated in self-referential processing (e.g. ventromedial prefrontal cortex) [44]. Moreover, self-related autobiographical and spatial memories share similar medial temporal neural substrates (e.g. hippocampus). There are conceptual similarities between memory for events in time and the spatial mapping and navigation of locations, including 'perspective-taking'. However, it is unclear how interdependent are the representations of self in time and place.

\section{Levels of Self-awareness}

The facets of self-awareness highlighted above are associated with dissociable target components of self-representation and distinct expressions of awareness. These abilities vary in the degree to which they draw upon higher (integrative) cognitive processing. Nevertheless, such expressions of self-awareness are manifest across different levels of complexity [45]. In this sense, self-awareness is not as simply as a function of either lower- or higher-order processing, but rather as a set of capacities transcending representational levels.

For example, a research framework for conceptualising interoceptive abilities distinguishes between interoceptive accuracy, sensibility, and awareness [17]. Accuracy can be defined as the objective ability to detect internal states, interoceptive sensibility represents dispositional tendencies to be internally self-focused, while metacognitive interoceptive awareness (insight) indicates the level of self-knowledge about the degree to which one can accurately judge interoceptive sensations [17]. Interestingly, dissociative symptoms, such as depersonalization, representing a symptomatic partial disturbance of self-representation, are associated with deficits in metacognitive interoception [46]. In relation to agency, a distinction is proposed between the feeling of agency and the judgement of agency. The feeling of agency captures implicit nonconceptual feelings of being an agent of action. In contrast, the higher-level explicit judgement of agency is influenced by prior knowledge, expectations, and beliefs [24, 47].

Similarly, self-awareness manifest through metacognition is not exclusively a higher-order process, since it involves early 'preconscious' representations, apparent for example in electrophysiological signatures of error-monitoring, such as the early error-related negativity (ERN) and subsequent error positivity $(\mathrm{Pe})$, which can be selectively compromised in neurological disorders [48]. Homologous mechanisms are shown to operate also in non-human primates [49], and, in humans, the Pe is associated with both awareness of error and accompanying psychophysiological responses [50]. Evidence from studies of children [51] and patients with neurodegenerative conditions $[52,53]$ also indicates that metacognitive processing can operate implicitly, impacting appraisals and decision-making of intermediate complexity. Metacognitive beliefs also enter into and self-appraisal of cognitive ability and performance at higher levels of complexity (e.g. [54]).

Even in the case of autobiographical memory, characterised conceptually as composed of episodic and semantic memories, varying levels of complexity in self-processing can be distinguished. For instance, implicit forms of memory, such as motor habits linked to procedural memory, embody important aspects of self-information that determine how to engage in actions and select between motor behaviours [55]. Potentially, low-level long-term representations, e.g. of a core 'biological self', not linked to autonoetic consciousness and re-experiencing, may be at the foundation of higher-order autobiographical memory processing. 


\section{Predictive Coding and Self-awareness}

A potential approach to understand self-awareness across levels of complexity is predictive coding (PC; [56]). Although empirical support for this notion is still emerging [57•], PC links different perspectives on brain function, ranging from the nineteenth-century pioneers [58] to current theoretical approaches [59]. In brief, this framework suggests that, in the absence of complete information about the world and faced with unpredictable conditions, the brain works as an inferential machine [59]. The brain generates predictions (expectancies or 'beliefs') that model the likely causes of incoming sensory information, to manage and extract knowledge from the wealth of these afferent signals. The PC framework proposes that the brain generally seeks to minimise mismatch (prediction error, i.e. sensory surprise) between 'descending' predictions and 'ascending' afferent sensory information. This can be achieved by adjusting the predictions, i.e. by learning (in order to change the beliefs or better trust the prediction through 'precision weighting'). Alternatively, one can change the incoming sensory information by acting on the world. Here, predictions/beliefs equate to action commands, sequences of which are termed policies. Both learning and 'active inference' increase knowledge about the sensory data.

PC accounts for both top-down and bottom-up influences in neural processing. This approach has already been applied in relation to self-awareness, for example in the context of agency [60], interoception [18••], and their potential interac-

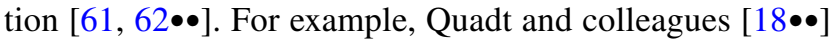
propose that descending higher-order predictions about inner bodily states, generated cortically, are compared to ascending visceral afferents. Mismatch is used both to refine interoceptive predictions and drive efferent autonomic 'actions', to reduce future predictive errors. Representation of self through interoceptive PC is hierarchical; the higher-order integrative representation (of desired internal bodily state based on previous experience) evokes interoceptive policies that drive top-down descending predictions that yoke lowerorder homeostatic reflexes and that are constantly compared with bottom-up bodily data.

A related mechanism (plausibly a direct extension of interoceptive PC with active inference, encompassing valenced motivational outcomes) is proposed to support higher-order emotional processing. Again, these principles may operate across varying levels of complexity of selfawareness. The theory of constructed emotion suggests there is an emotional paradox, with nonspecific autonomic activation triggering states that are perceived as a discrete emotion through higher-level appraisal of the (often external) context [63]. Within a PC perspective, a constructed emotion concept is thus a set of predictions about incoming sensory data (including change in interoceptive arousal) [63]. These predictions are again based on previous experience; emotional concepts categorise data patterns to generate discrete emotional experiences, are modified by incoming information, and support allostatic changes in physiology and behaviour, with longer-term adaptive value. In this model, emotional regulation controls the selection of regulatory actions through predictions that re-categorise both sensory data and emotional concepts, [63].

These theoretical formulations propose that top-down processing (i.e. predicting incoming information) is crucial to develop both a sense of interoceptive agency (core biological selfhood) and emotional processing/regulation (self as an emotional agent). Moreover, the same notion likely represents a wider feature of self-awareness: From this perspective, self-awareness can be thought of as the result of predictions dealing with incoming sensory data across different modalities. Top-down expectations, constructed upon previous knowledge and recurrent patterns of interaction with the world, shape and give coherence to bodily information, fostering the emergence of a broader sense of self-awareness. In situations in which predictions broadly match incoming signals, the regular feeling of self-awareness is experienced, whereas mismatches may lead to either adjustment of predictions and behaviour or, in the case of specific neurocognitive symptoms, impaired self-awareness, or delusional explanations for aberrant experiences.

Such a self-model, built through dynamic cross-modal multisensory integration of information, has a high degree of redundancy and, hence, is relatively immune to damage to underlying distributed neural substrates. However, certain sources of sensory data likely have a privileged position in the emergence of self-awareness. For instance, interoceptive imperatives (encoding physiological states necessary for survival) underpin emotional processes [64]. In turn, these contribute to a sense of self-presence and internal agency [61]. Similarly, given the embodied nature of our cognitive capacities, afferent information concerning action and goaldirected behaviour in the external environment may be particularly relevant for the emergence of a sense of self. This places continuous dynamic interoceptive bodily information at the core of a nested-hierarchy for self-representation [4, 5] upon which is built elaborated levels of self-processing and associated self-awareness.

This conceptual model is particularly relevant for the understanding of self-awareness in dementia, considering the profile of global cognitive impairment found in this condition, which may compromise top-down inferential processing of sensory information, and impact the discriminative quality of incoming sensory signals. However, before applying this framework to understand self-awareness in dementia, we review the expression of different facets of selfawareness in the context of neurodegenerative conditions. 


\section{Self-awareness in Dementia}

Alzheimer's disease (AD) is the most common form of neurodegenerative dementia, providing both a strong motivation and a model clinical condition for understanding self-awareness in dementia. AD is a well-characterised neuropsychiatric condition that presents with cognitive, behavioural, and functional deficits that progress in severity with disease duration. The core neuropathological features of AD include widespread neurodegeneration encompassing cortical regions and brain-wise networks that are implicated in supporting aspects of self-awareness. Clinically, people with AD may experience changes to multiple facets of self-awareness. The most well-characterised areas of self-awareness affected by AD are higher levels of autobiographical memory and metacognition.

\section{Autobiographical Memory}

Autobiographical self-awareness relies on both episodic and semantic memory, with the awareness of self that accompanies episodic memory referred to as autonoetic consciousness. This higher-level autobiographical awareness becomes impaired in mild/moderate AD; people with $\mathrm{AD}$ have a reduced subjective feeling of re-experiencing the past, with diminished self-imagery and less emotional salience when recalling autobiographical memories [65, 66, 67••]. However, in mild/moderate $\mathrm{AD}$, although there may also be some impaired retrieval of semantic information, there is typically a persistence of semantic knowledge of the self (e.g. elements of personal history) that maintains a preserved narrative sense of self $[67 \bullet \bullet, 68]$. This is not always the case for other subtypes of dementia; despite memory impairment in semantic dementia (SD), patients retain feelings of identity for past and present, but not for future selves [69]. Autobiographical memory in behavioural-variant frontotemporal dementia (bvFTD) has been less frequently explored, but results suggest impairments in self-related recollections irrespective of the time period. This may arise from specific compromising of retrieval strategies due to executive deficits [70]. More speculatively, selective depletion of Von Economo neurons in bvFTD may disrupt core interoceptive aspects of self-representation [28].

The narrative sense of self in $\mathrm{AD}$ may be associated with reduced awareness of recent changes in cognitive function and behaviour, due to an impaired ability to update and accurately monitor new self-information [71•]. This may give rise to a lack of awareness of new cognitive deficits, or anosognosia, which is a common feature of AD [72]. Anosognosia in $\mathrm{AD}$ is associated with neurodegenerative decreases in the structural and functional integrity of distributed brain regions, including frontal cortices, medial temporal lobe, anterior and posterior cingulate cortex, and insula [73••]. Anosognosia in dementia, reflecting limited awareness of a loss in cognitive ability, has also been explored through the concept of metacognition.

\section{Metacognition}

Metacognition, when applied to autobiographical information, can be investigated at a lower, less global level than in overall judgements of cognitive function, by assessing how well an individual can judge their performance accuracy during episodic or semantic memory tasks. In studies of people with early $\mathrm{AD}$, this online monitoring of cognitive performance yields some conflicting results: Metacognitive selfawareness of episodic and semantic memory performance is reported as remaining intact in some [74, 75], but not all, studies where impaired metacognition is expressed as both over- and underestimation of performance [76, 77]. Interestingly, even in cases of limited awareness of performance, PwD can still respond emotionally to tasks [51], persist more during periods of success than periods of failure [78], and allocate study time proportionately to the difficulty of selfrecollection [79]. These observations reveal the presence of 'implicit awareness' of self [10].

These conflicting results likely reflect how metacognition is defined and assessed, and also to the individual variation of metacognitive self-awareness in people with early AD. This would be underpinned by different profiles of cognitive impairment and underlying neuropathology. Correspondingly, impaired metacognition is particularly associated with localised structural and functional change involving frontal lobes, posterior cingulate cortex [80], and insula [81]. Given the involvement of frontal lobes in metacognition, unsurprisingly comparisons of people with $\mathrm{AD}$ and those with frontotemporal dementia (FTD) reveal that the latter group has more extensive metacognitive impairments, especially in bvFTD $[82,83]$.

\section{Emotion Regulation}

The self-awareness of one's own emotional state that is necessary for emotion regulation is also affected by dementia. The capacity for emotion regulation has been associated with components of executive function; for example, verbal fluency performance predicts the ability of PwD to regulate a range of emotional responses [84]. However, one study of people with moderate $\mathrm{AD}$ found no differences between $\mathrm{AD}$ and control groups on either self-reported subjective experience of emotion, nor the ability to inhibit emotion expressive behaviour, although behavioural amplification of emotion was affected [85]. People with AD also show heightened emotional contagion, which is the automatic echoing of the emotional states of others [86]. Affective lability of this sort 
is also observed following frontal lobe lesions and other conditions compromising response inhibition and impairing emotional regulation. Of note, in a recent study people with AD or FTD were shown films designed to elicit disgust and asked to watch or suppress their emotional response. FTD patients were more impaired in emotion suppression than people with $\mathrm{AD}$ or controls. Neuroimaging analysis of brain structure revealed that insula volume predicted the capacity for effective emotion regulation [87].

\section{Body Ownership and Agency}

Few studies have examined evidence of deficits in awareness of body ownership and/or proprioception in people with AD. However, people with dementia appear to show a preserved ability to identify their own body and express agency, which persists even into advanced severe stages of the disease. In one study, all people with moderate $\mathrm{AD}$ and $25 \%$ of people with severe AD were able to identify parts of their own bodies (e.g. able to indicate their elbow when asked) [88], and people with severe AD are able to use correct personal pronouns (e.g., 'I', 'me') with reference to themselves [e.g. 89] and to express self-related views [90•]. Relatedly, although studies suggest impairment of mirror self-recognition may occur in severe dementia (e.g. [91]); for example, with PwD seeing themselves in the mirror and thinking there is an intruder, behaviours such as grooming have been cited as evidence of covert self-identification [92].

Additional evidence for the preservation of agency in dementia comes from studies employing a phenomenological perspective, which can be particularly relevant given the constraints to measure agency through cognition in this condition. For instance, an agency in PwD may be observed through the analysis of bodily information, actions, and goal-directed behaviours, beyond standardised cognitive paradigms [93]. Within this framework, people with mild to moderate dementia may present difficulties in decision-making capacity but can demonstrate a sense of agency through behavioral and emotional responses, including emotional reflexivity through expressed feelings and desires, despite limited verbal ability [94].

\section{Interoception}

There is some evidence that interoception may be impaired in $\mathrm{AD}[95,96]$. In a study using a heartbeat detection paradigm, people with AD demonstrated impairment in levels of interoceptive accuracy and interoceptive awareness, typically overestimating their performance. The study also included a group of people with FTD and frontal stroke with deficits in interoception associated with volume loss in the anterior insula and fronto-temporal lobes [97]. Neurodegeneration of the posterior insula has also been implicated in the reduced interoceptive experience of temperature and pain in people with FTD [97].

\section{Summary of Findings}

There is some evidence that, despite higher-level impairment in autobiographical awareness, lower-level aspects of selfawareness, including indices of body ownership and agency, persist in $\mathrm{AD}$ enabling an ongoing persevered global sense of self-awareness (summarised in Table 2). Clinical evidence from people with $\mathrm{AD}$ nevertheless illustrates the multi-level and multi-faceted nature of self-awareness. The heterogeneity of self-awareness in AD, particularly at higher-order levels, is further supported by studies that assessed distinct targets of self-awareness $[98,99]$. One study quantified

Table 2 Self-awareness in dementia

\begin{tabular}{|c|c|c|}
\hline Self-awareness processes & Evidence in PwD & Clinical expression \\
\hline Interoception & $\begin{array}{l}\text { Impairments in interoceptive accuracy and aware- } \\
\text { ness }\end{array}$ & $\begin{array}{l}\text { Difficulties in estimating internal bodily states; over- } \\
\text { estimation of the interoceptive capacity }\end{array}$ \\
\hline Proprioception and body ownership & $\begin{array}{l}\text { Identification of own body and covert mirror self- } \\
\text { recognition even in severe dementia }\end{array}$ & $\begin{array}{l}\text { Use of personal pronouns, expression of self- } \\
\text { related views; grooming in front of mirrors when } \\
\text { prompted with cues }\end{array}$ \\
\hline Agency & $\begin{array}{l}\text { Impairments in the cognitive agency, but preserva- } \\
\text { tion through behavioural and emotional responses }\end{array}$ & $\begin{array}{l}\text { Expression of feelings and desires even in cases of } \\
\text { compromised language ability }\end{array}$ \\
\hline Metacognition & $\begin{array}{l}\text { Discrepant findings, but impairments especially in } \\
\text { cases of damage to frontal lobes }\end{array}$ & $\begin{array}{l}\text { Uncertainty when describing personal ability; } \\
\text { implicit adjustment to task difficulty }\end{array}$ \\
\hline Emotional regulation & $\begin{array}{l}\text { Impairments in suppression (FTD) or amplifica- } \\
\text { tion of emotions (AD); heightened emotional } \\
\text { contagion }\end{array}$ & Difficulties controlling emotions; agitation and anger \\
\hline Autobiographical memory & $\begin{array}{l}\text { Impairments in mild to moderate } \mathrm{AD} \text {, in particular } \\
\text { of episodic components; reverse memory gradient } \\
\text { in semantic dementia; strategic retrieval deficits } \\
\text { in bv FTD }\end{array}$ & $\begin{array}{l}\text { Persistent self-narratives, especially about the past; } \\
\text { difficulties in updating self-information }\end{array}$ \\
\hline
\end{tabular}


awareness, through the discrepancy between carers and PwD evaluation, of cognitive dysfunction, illness severity, emotional state, daily functioning, and social relationships [99]. The discrepancy scores differed between domains, interpreted as reflecting the heterogeneity of self-awareness in people with mild and moderate AD. Moreover, although levels of overall awareness, awareness of cognitive problems, and impaired functioning were worse in moderate compared to mild $\mathrm{AD}$, there was no significant difference between moderate and mild AD groups in awareness of emotional state [99]. These data provide evidence for domain-selective deficits in self-awareness in PwD, which in turn may relate to the patterned distribution of neurodegenerative processes and impact on the different demands of self-perceptions and judgements reflecting self-awareness in distinct domains $[6$, 99].

\section{Towards an Integrative Framework of Self-awareness in Dementia}

An important feature of selfhood in dementia is its typical persistence at a core level, even in severe stages of neurodegeneration. Few attempts have been made to understand this phenomenon from a neurobiological perspective, but recently, the notion of an emergent self is suggested to account for this $[100 \bullet \bullet]$. According to this perspective, the feeling of self is but the combination of a set of processes, with experiences from different sources, such as interoception, agency, autobiographical memory, and metacognition, leading to a higher-order property, including a unified phenomenological experience. This refers to a fundamental feature of our consciousness, namely its binding ability, or the sense of perceiving an experience as a unified whole instead of a combination of fragmentary elements. In dementia, this sense of selfhood may emerge from the combination of bodily, agentic, implicit, and mnemonic information, as well as recognising the important contributions of a surrogate (others) and extended (the environment) sources [100••]. The variety of these sources may explain the resilience of selfhood even towards later stages of dementia, highlighting that some of these processes may compensate for the impairment of others. At the neural level, a self-model, arising initially from interoceptive control processes and subsequently elaborated through dynamic cross-modal multisensory integration of diverse information across distributed neural substrates, may retain a high degree of redundancy and remain relatively immune to neurodegenerative damage.

Combining the notion of diverse self-processes that may lead to a solid sense of self in dementia, with a PC framework, provides the ground for the discussion of an integrative model of self-awareness in dementia. This model would embody notions of nested hierarchy within self-processes $[4$,
5], but and benefit from also from a finer empirical appreciation of how top-down and bottom-up self-referential processing may be affected by dementia.

Considering top-down influences, it is noted that PwD has stable but outdated personal information about themselves, with this having a likely impact on the estimation of self-ability. This is termed as a metaphor, a 'petrified self' [71•], and refers to the profile of mnemonic impairment caused by hippocampal damage: anterograde memory deficits coupled with retrograde memory difficulties with a gentle temporal gradient. Within a PC perspective, this may be linked to predictions, which are stable but, nevertheless, are not updated efficiently with incoming information.

In terms of future research, our formulation provides a blueprint for empirical studies aiming to explore self-awareness in dementia. Considering top-down mechanisms, investigating how the profile of cognitive impairment in different stages of dementia impact the formation of predictions may illuminate distortions of self-awareness. A key prediction, consistent with current findings, is that higher-order features of self-awareness would be more impaired than lowerorder processes. This may also help to explain the presence of psychological and behavioural symptoms of dementia, including psychotic symptoms (e.g. delusions, misidentification), which may emerge as an attempt to make sense of mismatches between predictions and sensory data.

In addition, exploring the level of preservation of different sensory signals can crucially help understand impaired self-awareness in dementia. In particular, studies with PwD will benefit from detailed characterization of low-level processing of interoceptive, body ownership, and agency sensory data, given the potential resilience of these processes in later stages of the condition and also how these may feed into higher-order self-awareness. For example, different aetiologies of dementia may be linked to diverse alterations of interoception, which may underlie changes in other forms of self-awareness, such as emotional regulation. The extent to which this may alter selfhood in dementia is especially relevant from a clinical perspective.

\section{Conclusion}

As indicated, self-awareness can be thought of as a constellation of different processes, which interact and are typically integrated to give rise to a unitary experience. These processes happen within a continuum of complexity, involving lower- and higher-order information. Evidence from PwD reinforce this notion, by highlighting the presence of a mixed profile of impairment and preservation, depending on the self-awareness process investigated and its level, moderated by clinical factors including the pathoetiological nature of dementia. The notion of an emergent self [100••] may help 
to explain, from a neurobiological perspective, how interaction between self-awareness processes may compensate for impaired self-awareness abilities and maintain a resilient sense of selfhood in PwD.

Exploring the diversity of self-awareness processes across dementia severity levels may help to determine the time course of alterations, with initial higher-order impairment linked to cortical damage and, later on, alterations associated with bottom-up processing. Clinically, such a research programme would have as its ultimate goal the development of care practices that acknowledge the extent of preservation of self-awareness in dementia and capitalise on preserved abilities to foster and maintain personhood as the condition progresses.

\section{Compliance with Ethical Standards}

Conflict of interest Dr. Mograbi reports grants from CNPq, grants from FAPERJ, during the conduct of the study. Dr. Huntley reports grants from Wellcome, during the conduct of the study. Dr. Critchley has nothing to disclose.

Human and animal rights This article does not contain any studies with human or animal subjects performed by any of the authors.

Open Access This article is licensed under a Creative Commons Attribution 4.0 International License, which permits use, sharing, adaptation, distribution and reproduction in any medium or format, as long as you give appropriate credit to the original author(s) and the source, provide a link to the Creative Commons licence, and indicate if changes were made. The images or other third party material in this article are included in the article's Creative Commons licence, unless indicated otherwise in a credit line to the material. If material is not included in the article's Creative Commons licence and your intended use is not permitted by statutory regulation or exceeds the permitted use, you will need to obtain permission directly from the copyright holder. To view a copy of this licence, visit http://creativecommons.org/licenses/by/4.0/.

\section{References}

Papers of particular interest, published recently, have been highlighted as:

- Of importance

$\bullet$ Of major importance

1. Smith H. The world's religions. San Francisco: HarperSanFrancisco; 1991.

2. Lou HC, Changeux JP, Rosenstand A. Towards a cognitive neuroscience of self-awareness. Neurosci Biobehav Rev 2017;01497634. https://doi.org/10.1016/j.neubiorev.2016.04.004.

3. Morin A. Self-Awareness Part 1: Definition, measures, effects, functions, and antecedents. Social Personal Psychol Comp. 2011;5:807-23. https://doi.org/10.1111/j.1751-9004.2011. 00387.x.
4. Damasio A. The feeling of what happens: body and emotion in the making of consciousness. Fort Worth, TX: Harcourt College Publishers; 1999.

5. Feinberg TE. The nested neural hierarchy and the self. Conscious Cognit 2010;20:951608. https://doi.org/10.1016/j.concog.2010. 09.016 .

6. Marková IS, Clare L, Whitaker CJ, Roth I, Nelis SM, Martyr A, Roberts JL, Woods RT, Morris R. Phenomena of awareness in dementia: heterogeneity and its implications. Conscious Cognition. 2014;25:17-26. https://doi.org/10.1016/j.concog.2014.01. 008.

7. Mograbi DC, Morris RG. Anosognosia Cortex. 2018;103:385-6. https://doi.org/10.1016/j.cortex.2018.04.001. This paper provides definitions, agreed by a panel of specialists, for a number of concepts used in the current article.

8. Williams, DM. Theory of own mind in autism: evidence of a specific deficit in self-awareness? Autism: International Journal of Research and Practice 2010;1461-7005. https://doi.org/10. $1177 / 1362361310366314$.

9. Harrison BE, Son GR, Kim J, Whall AL. Preserved implicit memory in dementia: a potential model for care. Am J Alzheimer's Dis Other Dementias® 2007;286-293. https://doi.org/10. 1177/1533317507303761.

10. Mograbi DC, Morris RG. Implicit awareness in anosognosia: clinical observations, experimental evidence, and theoretical implications. Cogn Neurosci. 2013;4:3-4. https://doi.org/10. 1080/17588928.2013.833899.

11. Favrod J, Rexhaj S, Bardy S, Ferrari P, Hayoz C, Moritz S, Bonsack C. Sustained antipsychotic effect of metacognitive training in psychosis: a randomized-controlled study. Eur Psychiatry. 2014;29(5):275-81. https://doi.org/10.1016/j.eurpsy.2013.08. 003.

12. Haffner P, Quinlivan E, Fiebig J, et al. Improving functional outcome in bipolar disorder: a pilot study on metacognitive training. Clin Psychol Psychother. 2018;25:50-8. https://doi.org/10.1002/ cpp.2124.

13. Sabat SR. Excess disability and malignant social psychology: a case study of Alzheimer's disease. J Commun Appl Soc Psychol. 1994;4:157-66. https://doi.org/10.1002/casp.2450040303.

14. Craig, A. How do you feel? Interoception: the sense of the physiological condition of the body. Nature Reviews Neuroscience 2002;3655-666. https://doi.org/10.1038/nrn894.

15. Critchley HD, Wiens S, Rotshtein P, Ohman A, Dolan RJ. Neural systems supporting interoceptive awareness. Nat Rev Neurosci. 2004;7:189-95. https://doi.org/10.1038/nn1176.

16. Craig ADB. How Do You Feel? An interoceptive moment with your neurobiological self. New Jersey: Princeton University Press; 2014.

17. Garfinkel SN, Seth AK, Barrett AB, Suzuki K, Critchley HD. Knowing your own heart: distinguishing interoceptive accuracy from interoceptive awareness. Biological Psychology 2015;0301-051. https://doi.org/10.1016/j.biopsycho.2014.11. 004.

18.• Quadt L, Critchley HD, Garfinkel SN. The neurobiology of interoception in health and disease. Ann N Y Acad Sci. 2018;14281:112-28. https://doi.org/10.1111/nyas.13915. This paper reviews the neurobiological mechanisms of interoception and their alterations in clinical groups.

19. Critchley HD. Neural mechanisms of autonomic, affective, and cognitive integration. J Comparat Neurol. 2005;5(4931):154-66. https://doi.org/10.1002/cne.20749.

20. Serino A, Alsmith A, Costantini M, Mandrigin A, TajaduraJimenez A, Lopez C. Bodily ownership and self-location: components of bodily self-consciousness. Consciousness and Cognition 2013;1053-8100. https://doi.org/10.1016/j.concog.2013.08. 013. 
21. Kenzie JM, Ben-Shabat E, Lamp G, et al. Illusory limb movements activate different brain networks than imposed limb movements: an ALE meta-analysis. Brain Imaging Behav. 2018;12:919-30. https://doi.org/10.1007/s11682-01797561.

22. Gandola M, Invernizzi P, Sedda A, Ferrè ER, Sterzi R, Sberna M, Paulesu E, Bottini G. An anatomical account of somatoparaphrenia. Cortex. 2012;489:1165-78. https://doi.org/10.1016/j. cortex.2011.06.012.

23. Haggard P. Sense of agency in the human brain. Nat Rev Neurosci. 2017;18:196-207. https://doi.org/10.1038/nrn.2017.14.

24. Moore JW. What is the sense of agency and why does it matter? Front Psychol 2016;1272. https://doi.org/10.3389/fpsyg.2016. 01272.

25. Zito GA, Wiest R, Aybek S. Neural correlates of sense of agency in motor control: A neuroimaging meta-analysis. PLoS ONE. 2020;156:0234321. https://doi.org/10.1371/journal.pone.02343 21.

26. Critchley HD, Mathias CJ, Dolan RJ. Neural activity in the human brain relating to uncertainty and arousal during anticipation. Neuron. 2001;292:537-45. https://doi.org/10.1016/s08966273(01)00225-2.

27. Evrard HC, Forro T, Logothetis NK. Von Economo neurons in the anterior insula of the macaque monkey. Neuron. 2012;74(3):482-9. https://doi.org/10.1016/j.neuron.2012.03. 003.

28. Critchley H, Seth A. Will studies of macaque insula reveal the neural mechanisms of self-awareness? Neuron. 2012;74(3):423-6. https://doi.org/10.1016/j.neuron.2012.04. 012 .

29. Flavell J H. Speculations about the nature and development of metacognition. In: Weinert FE, Kluwe RH, editors. Metacognition, Motivation and Understanding. New Jersey: Lawrence Erlbaum Associates; 1987.

30. Fleming SM, Dolan RJ. The neural basis of metacognitive ability Philosophical Transactions of the Royal Society of London Series B. Biological Sciences. 2012;193671594:1338-49. https://doi.org/10.1098/rstb.2011.0417.

31. Gehring WJ, Liu Y, Orr J.M, Carp J. The error-related negativity (ERN/Ne). In: Luck SJ, Kappenman ES, editors. The Oxford handbook of event-related potential components. London: Oxford University Press; 2011.

32. Critchley HD, Tang J, Glaser D, Butterworth B, Dolan RJ. Anterior cingulate activity during error and autonomic response. Neuroimage. 2005;27(4):885-95. https://doi.org/10.1016/j.neuro image.2005.05.047.

33. Rolls ET, Cheng W, Feng J. The orbitofrontal cortex: reward, emotion and depression. Brain Community. 2020;22:fcaa196. https://doi.org/10.1093/braincomms/fcaa196.

34.• Vaccaro AG, Fleming SM. Thinking about thinking: a coordinate-based meta-analysis of neuroimaging studies of metacognitive judgements. Brain Neurosci Adv. 2018. https://doi.org/10. 1177/2398212818810591. This paper summarizes current evidence on neural correlates of metacognition, meta-analyzing existing data.

35. Beran MJ, Menzel CR, Parrish AE, Perdue BM, Sayers K, Smith JD, Washburn DA. Primate cognition: attention, episodic memory, prospective memory, self-control, and metacognition as examples of cognitive control in nonhuman primates. WIREs Cognit Sci. 2016;7:294-316. https://doi.org/10.1002/wcs.1397.

36. Insabato A, Pannunzi M, Deco G. Neural correlates of metacognition: a critical perspective on current tasks. Neurosci Biobehav Rev 2016;0149-7634. https://doi.org/10.1016/j.neubiorev.2016. 08.030 .

37. Gross JJ. Emotion regulation: taking stock and moving forward. Emotion 2013; 133:359-365. https://doi.org/10.1037/ a0032135.
38. Peña-Sarrionandia A, Mikolajczak M, Gross JJ. Integrating emotion regulation and emotional intelligence traditions: a metaanalysis. Front Psychol 2015;1664-1078. https://doi.org/10. 3389/fpsyg.2015.00160.

39. Hou J, Song B, Chen ACN, Sun C, Zhou J, Zhu H, Beauchaine TP. Review on neural correlates of emotion regulation and music: implications for emotion dysregulation. Front Psychol 2017;1664-1078. https://doi.org/10.3389/fpsyg.2017.00501.

40. Ochsner KN, Gross JJ. The cognitive control of emotion. Trends Cognit Sci 2005;1364-6613. https://doi.org/10.1016/j.tics.2005. 03.010.

41. Rosenbaum RS, Kohler S, Schacter DL, Moscovitch M, Westmacott R, Black SE, et al. The case of K.C.: contributions of a memory-impaired person to memory theory. Neuropsychologia. 2005;43:989-1021. https://doi.org/10.1016/j.neuropsychologia. 2004.10.007.

42. Maguire E. Neuroimaging studies of autobiographical event memory. Philosophical Transact Royal Soc London Ser B Biol Sci. 2001;356:1441-51. https://doi.org/10.1098/rstb.2001.0944.

43. Holland AC, Addis DR, Kensinger EA. The neural correlates of specific versus general autobiographical memory construction and elaboration. Neuropsychologia. 2011;49:3164-77. https:// doi.org/10.1016/j.neuropsychologia.2011.07.015.

44. Renoult L, Davidson PS, Palombo DJ, Moscovitch M, Levine B. Personal semantics: at the crossroads of semantic and episodic memory. Trends Cognit Sci. 2012;1611:550-8. https://doi.org/ 10.1016/j.tics.2012.09.003.

45. Morin A. Levels of consciousness and self-awareness: a comparison and integration of various neurocognitive views. Conscious Cognit 2006;152358-371. https://doi.org/10.1016/j.concog.2005.09.006.

46. Pick S, Rojas-Aguiluz M, Butler M, Mulrenan H, Nicholson TR, Goldstein LH. Dissociation and interoception in functional neurological disorder. Cognit Neuropsychiatry. 2020;25(4):294311. https://doi.org/10.1080/13546805.2020.1791061.

47. Synofzik M, Vosgerau G, Newen A. Beyond the comparator model: a multifactorial two-step account of agency. Conscious Cognit 2008;1053-8100. https://doi.org/10.1016/j.concog.2007. 03.010 .

48. Lenzoni S, Baker J, Sumich AL, Mograbi DC. New insights into neural networks of error monitoring and clinical implications: a systematic review of ERP studies in neurological diseases. Rev Neurosci 2021. https://doi.org/10.1515/revneuro-2021-0054. Online ahead of print.

49. Godlove DC, Emeric EE, Segovis CM, Young MS, Schall JD, Woodman GF. Event-related potentials elicited by errors during the stop-signal task. I Macaque monkeys J Neurosci. 2011;31:15640-9. https://doi.org/10.1523/jneurosci.3349-11.

50. Hajcak G, McDonald N, Simons RF. To error is autonomic: error-related brain potentials, ANS activity, and post-error compensatory behavior. Psychophysiology. 2003;40(6):895-903. https://doi.org/10.1111/1469-8986.00107.

51. Paulus M, Proust J, Sodian B. Examining implicit metacognition in 3.5-year-old children: an eye-tracking and pupillometric study. Front Psychol. 2013;4:145. https://doi.org/10.3389/fpsyg.2013. 00145.

52. Mograbi DC, Brown RG, Salas C, Morris RG. Emotional reactivity and awareness of task performance in Alzheimer's disease. Neuropsychologia. 2012;50:2075-84. https://doi.org/10.1016/j. neuropsychologia.2012.05.008.

53. Souchay C, Moulin CJ. Eliciting the implicit: metacognition in Alzheimer's disease. Cognit Neurosci. 2013;4:203-4. https://doi. org/10.1080/17588928.2013.853657.

54. Frank DJ, Kuhlmann BG. More than just beliefs: experience and beliefs jointly contribute to volume effects on 
metacognitive judgments. J Exper Psychol: Learn Memory Cognit. 2017;43:680-93. https://doi.org/10.1037/xlm0000332.

55. Doll BB, Shohamy D, Daw ND. Multiple memory systems as substrates for multiple decision systems. Neurobiol Learn Mem. 2015;117(4):13. https://doi.org/10.1016/j.nlm.2014.04.014.

56. Rao RP, Ballard DH. Predictive coding in the visual cortex: a functional interpretation of some extra-classical receptive-field effects. Nat Rev Neurosci 1999;279-87. https://doi.org/10.1038/ 4580.

57. Heilbron M, Chait M. Great expectations: is there evidence for predictive coding in auditory cortex? Neuroscience. 2018;1389:54-73. https://doi.org/10.1016/j.neuroscience.2017. 07.061. This paper explores critically existing evidence for the predictive coding framework, particularly in relation to auditory processing.

58. Helmholtz H. In: Treatise on physiological optics. New York: Dover; 1866/1962.

59. Friston K, Kilner J, Harrison L. A free energy principle for the brain. J Physiol-Paris. 2006;100(1-3):70-87. https://doi.org/10. 1016/j.jphysparis.2006.10.001.

60. Kannape OA, Blanke O. Agency, gait and self-consciousness. Int J Psychophysiol. 2012;832:191-9. https://doi.org/10.1016/j. ijpsycho.2011.12.006.

61. Seth A, Suzuki K, Critchley H. An interoceptive predictive coding model of conscious presence. Front Psychol 2012;16641078. https://doi.org/10.3389/fpsyg.2011.00395.

62.• Marshall AC, Gentsch A, Schütz-Bosbach S. The interaction between interoceptive and action states within a framework of predictive coding. Front Psychol 2018;1664-1078. https://doi. org/10.3389/fpsyg.2018.00180. This article explores the interaction between interoception and agency, within a predictive coding framework.

63. Barrett LF. The theory of constructed emotion: an active inference account of interoception and categorization. Soc Cognit Affect Neurosci 2017;1-23. https://doi.org/10.1093/scan/ nsw154.

64. Critchley HD, Garfinkel SN. Interoception and emotion. Curr Opin Psychol. 2017;7:142352-3250. https://doi.org/10.1016/j. copsyc.2017.04.020

65. Piolino P, Desgranges B, Belliard S, Matuszewski V, Lalevée C, Sayette VDL, Eustache F. Autobiographical memory and autonoetic consciousness: triple dissociation in neurodegenerative diseases. Brain. 2003;2203:2219. https://doi.org/10.1093/brain/ awg222.

66. Irish M, Lawlor BA, O’Mara SM, Coen RF. Impaired capacity for autonoetic reliving during autobiographical event recall in mild Alzheimer's disease. Cortex 2011;236-49. https://doi.org/ 10.1016/j.cortex.2010.01.002.

67.• Strikwerda-Brown C, Grilli MD, Andrews-Hanna J, Irish M. "All is not lost"- Rethinking the nature of memory and the self in dementia. Ageing Res Rev 2019;1568-1637. https://doi. org/10.1016/j.arr.2019.100932. This excellent paper explores the resilience of a sense of self across different subtypes of dementia.

68. Addis DR, Tippett LJ. Memory of myself: autobiographical memory and identity in Alzheimer's disease. Memory. 2004;12:56-74. https://doi.org/10.1080/09658210244000423.

69. Duval C, Desgranges B, Sayette VDL, Belliard S, Eustache F, Piolino P. What happens to personal identity when semantic knowledge degrades? A study of the self and autobiographical memory in semantic dementia. Neuropsychologia. 2012;502:254-65. https://doi.org/10.1016/j.neuropsychologia. 2011.11.019.

70. Irish M, Hornberger M, Lah S, Miller L, Pengas G, Nestor PJ, et al. Profiles of recent autobiographical memory retrieval in semantic dementia, behavioural-variant frontotemporal dementia, and Alzheimer's disease. Neuropsychologia. 2011;49:2694-702. https://doi.org/10.1016/j.neuropsychologia. 2011.05.017.

71. Lenzoni S, Morris RG, Mograbi DC. The petrified self 10 years after: current evidence for mnemonic anosognosia. Front Psychol. 2020;11:465. https://doi.org/10.3389/fpsyg.2020.00465. This paper reviews evidence from the past decade on the contribution of memory impairment to loss of self-awareness in dementia.

72. Starkstein SE. Anosognosia in Alzheimer's disease: diagnosis, frequency, mechanism and clinical correlates. Cortex. 2014;61:64-73. https://doi.org/10.1016/j.cortex.2014.07.019.

73.• Hallam B, Chan J, Gonzalez CS, Bhome R, Huntley J. What are the neural correlates of meta-cognition and anosognosia in Alzheimer's disease? A systematic review. Neurobiol Aging. 2020;94:250-64. https://doi.org/10.1016/j.neurobiolaging.2020. 06.011. This very recent paper reviews available evidence on neural correlates of anosognosia in AD.

74. Massimo L, Libon DJ, Chandrasekaran K, et al. Self-appraisal in behavioural variant frontotemporal degeneration Journal of Neurology. Neurosurg Psychiatry. 2013;84:148-53. https://doi. org/10.1136/jnnp-2012-303153.

75. Cosentino S, Brickman AM, Griffith E, Habeck C, Cines S, Farrell M, Shaked D, Huey ED, Briner T, Stern Y. The right insula contributes to memory awareness in cognitively diverse older adults. Neuropsychologia 2015;163-69. https://doi.org/10. 1016/j.neuropsychologia.2015.05.032.

76. Masaru M. Memory impairment and awareness of memory deficits in early-stage Alzheimer's disease. Tohoku J Exper Med. 2008;2015:133-40. https://doi.org/10.1620/tjem.215. 133.

77. Dodson CS, Spaniol M, O'Connor MK, Deason RG, Ally BA, Budson AE. Alzheimer's disease and memory-monitoring impairment: Alzheimer's patients show a monitoring deficit that is greater than their accuracy deficit. Neuropsychologia. 2011;49:2609-18. https://doi.org/10.1016/j.neuropsychologia. 2011.05.008.

78. Bomilcar I, Morris RG, Brown RG, Mograbi DC. Implicit behavioral change in response to cognitive tasks in Alzheimer disease. Cogn Behav Neurol. 2018;31:2-12. https://doi.org/10. 1097/WNN.0000000000000145.

79. Souchay C, Moulin CJ. Eliciting the implicit: metacognition in Alzheimer's disease. Cogn Neurosci. 2013;4:203-4. https://doi. org/10.1080/17588928.2013.853657.

80. Genon S, Simon J, Bahri MA, Collette F, Souchay C, Jaspar M, Bastin C, Salmon E. Relating pessimistic memory predictions to Alzheimer's disease brain structure. Cortex 2016;151-64. https://doi.org/10.1016/j.cortex.2016.09.014.

81. Bertrand E, Azar M, Rizvi B, Brickman AM, Huey ED, Habeck C, Landeira-Fernandez J, Mograbi DC, Cosentino S. Cortical thickness and metacognition in cognitively diverse older adults. Neuropsychology 2018;32:6700-710. https://doi.org/ 10.1037/neu0000458.

82. Eslinger PJ, Dennis K, Moore P, Antani S, Hauck R, Grossman M. Metacognitive deficits in frontotemporal dementia. J Neurol Neurosurg Psychiatry. 2005;7612:1630-5. https://doi.org/10. 1136/jnnp.2004.053157.

83. Rosen HJ, Alcantar O, Zakrzewski J, Shimamura AP, Neuhaus J, Miller BL. Metacognition in the behavioral variant of frontotemporal dementia and Alzheimer's disease. Neuropsychology 2014;28(3):436-47. https://doi.org/10.1037/neu0000012.

84. Gyurak A, Goodkind MS, Kramer JH, Miller BL, Levenson RW. Executive functions and the down-regulation and up-regulation of emotion. Cogn Emot. 2012;26:1103-18. https://doi.org/10. 1080/02699931.2011.557291. 
85. Henry JD, Rendell PG, Scicluna A, Jackson M, Phillips LH. Emotion experience, expression, and regulation in Alzheimer's disease. Psychol Aging. 2009;241:252-7. https://doi.org/10. 1037/a0014001.

86. Sturm VE, Yokoyama JS, Seeley WW, Kramer JH, Miller BL, Rankin KP. Emotional contagion in Alzheimer's disease. Proceedings of the National Academy of Sciences 2013;110(24):9944-49. https://doi.org/10.1073/pnas.13011 19110.

87. Muhtadie L, Haase CM, Verstaen A, Sturm VE, Miller BL, Levenson RW. Neuroanatomy of expressive suppression: the role of the insula. Emotion 2019;212:405-18. https://doi.org/10.1037/ emo0000710

88. Grewal RP. Self-recognition in dementia of the Alzheimer type. Percept Motor Skills 1994;792:1009-10. https://doi.org/10. 2466/pms.

89. Mayhew PA, Acton GJ, Yauk S, Hopkins BA. Communication from individuals with advanced DAT: can it provide clues to their sense of self-awareness and well-being? Geriatric Nursing 2001; 106-10. https://doi.org/10.1067/mgn.2001.115198.

90.• Fuchs T. Embodiment and personal identity in dementia. Med Health Care Philos. 2020;234:665-76. https://doi.org/10.1007/ s11019-020-09973-0. This paper weaves nicely concepts from philosophy with existing evidence on embodiment in dementia, exploring personal identity in the condition.

91. Biringer F, Anderson JR. Self-recognition in Alzheimer's disease: a mirror and video study. J Gerontol. 1992;476:P385-8. https://doi.org/10.1093/geronj/47.6.p385.

92. Bologna SM, Camp CJ. Covert versus overt self-recognition in late stage Alzheimer's disease. J Int Neuropsychol Soc. 1997;32:195-8.

93. Kontos P, Martin W. Embodiment and dementia: exploring critical narratives of selfhood, surveillance, and dementia care. Dementia. 2013;12:288-302. https://doi.org/10.1177/14713 01213479787.

94. Boyle G, Warren L. Showing how they feel: the emotional reflexivity of people with dementia. Families Relation Soc.
2017;6:3-19. https://doi.org/10.1332/204674315X1432817537 6100.

95. García-Cordero I, Sedeño L, de la Fuente L, Slachevsky A, Forno G, Klein F, et al. Feeling, learning from and being aware of inner states: interoceptive dimensions in neurodegeneration and stroke. Philosophical Transact Royal Soc London Biol Sci. 2016;371:20160006. https://doi.org/10.1098/rstb.2016.0006.

96. Tsakiris M, Critchley. Interoception beyond homeostasis: affect, cognition and mental health. Philosophical Transact Royal Soc London 2016;0002. https://doi.org/10.1098/rstb.2016.0002.

97. Fletcher PD, Downey LE, Golden HL, Clark CN, Slattery, Paterson RW, Rohrer JD, Schott JM, Rossor MN, Warren JD. Pain and temperature processing in dementia: a clinical and neuroanatomical analysis. Brain 2015;3360-72. https://doi.org/10.1093/ brain/awv276

98. Bertrand E, Mograbi DC, Brown RG, Landeira-Fernandez J, Morris RG. Heterogeneity of anosognosia in Alzheimer's disease according to the object of awareness. Psychol Neurosc. 2019;122282:290. https://doi.org/10.1037/pne0000164.

99. Lacerda IB, Santos RL, Belfort T, Neto JPS, Dourado MCN. Patterns of discrepancies in different objects of awareness in mild and moderate. Alzheimer's Dis Aging Mental Health. 2021;24:5789-96. https://doi.org/10.1080/13607863.2018. 1544219.

100.• Bomilcar Iris, Bertrand Elodie, Morris Robin G., Mograbi Daniel C. The seven selves of dementia. Front Psychiatry 2021;12519. https://doi.org/10.3389/fpsyt.2021.646050. This paper reviews different self-processes in dementia, suggesting a framework to understand the resilience of selfhood, from a neurobiological perspective, in this condition.

Publisher's Note Springer Nature remains neutral with regard to jurisdictional claims in published maps and institutional affiliations. 